Dossiê Especial: Experiências do PIBID na formação inicial e continuada de professores de línguas estrangeiras

HIBARINO \& NODARI (orgs)

Revista X, vol.1, 2015

\title{
O TEXTO LITERÁRIO ALIADO À TECNOLOGIA NA SALA DE AULA DE LÍNGUA INGLESA EM UMA ESCOLA PÚBLICA — POR UMA PROPOSTA PÓS-MÉTODO CENTRADA NO LETRAMENTO CRÍTICO E NA COMPREENSÃO DE INGLÊS COMO LÍNGUA INTERNACIONAL
}

The literary text associated to technology in the English language class in a public school - a post-method proposal centered on critical literacy and on the notion of English as an international language ${ }^{1}$

\author{
Ivana Chagas Lima LOBATO2 \\ Thais Carvalho LOPES ${ }^{3}$ \\ Rud Allyson MATOSO ${ }^{4}$ \\ Janice Inês NODARI ${ }^{5}$
}

Resumo: Este artigo tem como objetivo descrever a proposta de trabalho com o texto literário do gênero "conto" desenvolvida por bolsistas do programa PIBID - Inglês, em contexto de escola pública com alunos de ensino médio. A proposta foi elaborada no formato de oficina ${ }^{6}$ e contou com a participação de alunos e da professora supervisora da escola, os quais fizeram uso da ferramenta Facebook ${ }^{\circ}$ como meio de interação. A proposta se pautou primordialmente nos pressupostos do letramento crítico (JORDÃO, 2007), na noção de pós-método (KUMARAVADIVELU, 2001; 2006), e na compreensão de inglês como língua internacional (MCKAY, 2003; SHARIFIAN, 2009). Contou, ainda, com pressupostos fornecidos por diferentes estudiosos acerca da utilidade do uso do texto literário como ferramenta pedagógica e cultural na aula de Língua Inglesa. Observou-se que uma das grandes contribuições da oficina foi colocar a teoria em prática ao lidar com os desafios da articulação entre literatura e tecnologia, e com a desconstrução da ideia de que literatura e língua inglesa são difíceis e inacessíveis.

Palavras-chave: PIBID - Inglês; Literatura; Letramento crítico; Abordagem pós-método.

Abstract: This article aims at describing the proposal of working with the literary text - short story proposed by the interns of the PIBID - Inglês program, with high school students of a public school.

\footnotetext{
${ }^{1}$ Agradecemos a Denise Hibarino pela supervisão dos trabalhos desenvolvidos, pela paciência, e pela imprescindível contribuição e leitura acurada de versões anteriores deste texto.

${ }^{2}$ Graduanda em Letras na Universidade Federal do Paraná. Ivana.clll@ hotmail.com.

${ }^{3}$ Graduanda em Letras na Universidade Federal do Paraná. thaistcl@ gmail.com

${ }^{4}$ Graduando em Letras na Universidade Federal do Paraná. Kbrucio@ hotmail.com.

${ }^{5}$ Mestre em Letras. Professora da Universidade Federal do Paraná. jinodari@ yahoo.com.

${ }^{6}$ Salientamos que a proposta foi elaborada pelos bolsistas em 2013. A professora Janice Inês Nodari, coordenadora do projeto durante o ano de 2014, participa como co-autora deste texto.
} 
Dossiê Especial: Experiências do PIBID na formação inicial e continuada de professores de línguas estrangeiras

HIBARINO \& NODARI (orgs)

Revista X, vol.1, 2015

Making use of Facebook ${ }^{\mathrm{TM}}$ as a means of interaction, the proposal was designed in the format of a workshop, with the participation of the students and the supervising teacher of the school. The proposal was based on the critical literacy theoretical assumptions (JORDÃO, 2007), on the notion of post-method (KUMARAVADIVELU, 2001; 2006), and on the understanding of English as an international language (MCKAY, 2003; SHARIFIAN, 2009). It also found support on the justifications proposed by different scholars about the worth of using the literary text as an educational and cultural tool in the English language class. One of the main contributions of the proposal was putting theory into practice while dealing with the challenges of articulating literature and technology and with the deconstruction of the idea that literature and English are out of the way and difficult.

Keywords: PIBID - English; Literature; Critical literacy; Post-method approach.

\section{Introdução}

O Programa Institucional de Bolsa de Iniciação à Docência (PIBID) tem como objetivo proporcionar a alunos de licenciatura, na condição de bolsistas do programa, a oportunidade de entrar em contato com a realidade da escola pública já nos anos iniciais de sua formação, além de permitir que as teorias discutidas no âmbito acadêmico e desenvolvidas por formadores de professores sejam colocadas em prática, ideia esta que vai de encontro aos pressupostos do letramento crítico (LC) e dos estudos acerca da compreensão da língua inglesa como língua internacional [ILI], conceitos estes a serem esclarecidos mais adiante.

No entanto, a despeito de oportunidades como a oferecida pelo PIBID, é ainda perceptível no sistema educacional brasileiro atual a falta de diálogo entre a teoria e a prática, fazendo com que o professor, tanto em formação inicial quanto continuada, transite no que Kumaravadivelu considera serem "dois mundos pedagógicos: o mundo com base no método que é imposto a eles, e um mundo metodológico que é improvisado por eles." (2006, p. 170, tradução nossa) ${ }^{7}$. Vem daí a importância do desenvolvimento de propostas dentro de programas da natureza do PIBID e de seu compartilhamento em forma de relatos, como o que aqui se faz.

Caracterizando-se como um programa mais recente, o PIBID abrange diversas licenciaturas dentro das universidades brasileiras, incluindo a Universidade Federal do Paraná (UFPR), sendo Letras - Inglês uma delas. Para permitir o contato dos futuros docentes de língua inglesa com a escola pública, cada projeto do programa conta com o apoio de pelo menos ${ }^{8}$ dois

\footnotetext{
${ }^{7}$ No original: "two pedagogic worlds: a method-based one that is imposed on them, and a methodological one that is improvised by them." (KUMARAVADIVELU, 2006, p. 170).

${ }^{8} \mathrm{O}$ número de escolas participantes varia de acordo com cada projeto.
} 
Dossiê Especial: Experiências do PIBID na formação inicial e continuada de professores de línguas estrangeiras

HIBARINO \& NODARI (orgs)

Revista X, vol.1, 2015

colégios da rede pública, cada um com um supervisor, ou seja, um professor formado na disciplina do projeto em questão, também a ser chamado adiante de professor(a), que cede uma parte de suas aulas para a observação e a prática dos bolsistas. No caso do projeto de Inglês da UFPR, os colégios participantes são: Colégio Estadual Pilar Maturana e Colégio Professor Algacyr Munhoz Maeder, ambos localizados no Bairro Alto, em Curitiba, Paraná, e com IDEB igual ou inferior a 4 em 2011, de acordo com o portal do INEP (Instituto Nacional de Estudos e Pesquisas Educacionais Anísio Teixeira) ${ }^{9}$, fonte de divulgação dos dados. O IDEB de cada escola é obtido através de uma junção da análise dos percentuais de aprovação e aprendizado dos estudantes, definido por meio de testes de proficiência em português e matemática. Apresentar IDEB baixo seria uma das condições para a entrada do PIBID na escola ou colégio.

Para a condução da proposta, apresentada na sequência, optamos por realizar o trabalho no Colégio Pilar Maturana, por dois motivos. O primeiro motivo dizia respeito à faixa etária dos alunos, pois a proposta havia sido desenvolvida para turmas de ensino médio, com alunos entre 14-17 anos, encontrados, nesse cenário sócio educacional, em número suficiente para que ela pudesse ser desenvolvida. O segundo motivo dizia respeito ao IDEB da escola $(3,8)$, sendo o menor se comparado ao da outra instituição participante. Em um contexto como esse poderia ser de se esperar o baixo interesse em ler em língua estrangeira. Acreditamos que inserir as literaturas de língua inglesa no ensino médio é despertar o interesse dos alunos e fazê-los perceber que ler em inglês possibilita criação de sentidos, novos mundos e uma possível escolha profissional.

No primeiro momento, foi-nos proposto um período de observação do cotidiano da professora supervisora, durante o qual pudemos conhecer os alunos e o ambiente em que estavam inseridos, bem como observar as estratégias de ensino de língua inglesa utilizadas, as quais foram posteriormente debatidas no tocante à sua funcionalidade, sugerindo-se possíveis alterações. Após o período de observação, foi-nos proposto que desenvolvêssemos projetos baseados em nossas experiências como alunos de escolas públicas, observações das aulas, e discussões teóricas. Dentro desta proposta, procuramos desenvolver um trabalho, na forma de uma oficina, que, além de fazer uso do texto literário como ferramenta de ensino de língua inglesa promotora

\footnotetext{
9 Para mais informações, verificar o site do INEP: http://portal.inep.gov.br/visualizar//asset_publisher/6AhJ/content/novo-portal-mostra-desempenho-de-escolas-em-seu-contextosocial?redirect $=\mathrm{http} \% 3 \mathrm{a} \% 2 \mathrm{f} \% 2 \mathrm{fportal}$.inep.gov.br\%2f. Acesso em 11.01.2015.
} 
Dossiê Especial: Experiências do PIBID na formação inicial e continuada de professores de línguas estrangeiras

HIBARINO \& NODARI (orgs)

Revista X, vol.1, 2015

de participação social, pudesse verificar a receptividade dos alunos quanto à utilização de plataformas digitais para a comunicação e o compartilhamento de informações. A proposta desenhada será apresentada na sequência.

Este artigo está organizado em quatro partes. A primeira trata da apresentação da proposta, com breve resumo dos procedimentos adotados. A seção seguinte traz a contribuição da literatura para o ensino de língua inglesa, uma vez que o texto literário inspirou o trabalho desenvolvido. Em seguida, apontamos os benefícios advindos do uso de tecnologia em sala de aula e finalizamos com as considerações finais apontando pontos positivos e não tão positivos acerca da proposta.

\section{Metodologia? Estratégia de ensino? - uma proposta diferenciada unindo literatura e tecnologia}

O tema Releituras de Poe, escolhido para nossa oficina, foi inspirado em outro trabalho, conduzido pela professora supervisora durante os meses de observação, sobre a vida e a obra do poeta e dramaturgo inglês William Shakespeare. Ao observar a execução da pesquisa sobre o referido autor por parte dos alunos e suas apresentações, sentimo-nos motivados a trabalhar um tópico relacionado à literatura de língua inglesa com uma abordagem diferenciada. Levamos em conta o fato de que, apesar dos esforços da professora de tornar o tópico interessante, havia relutância dos alunos em relação ao tema, pois consideravam seus conhecimentos aquém do que era requerido para a compreensão de tal material, o que nos leva a refletir sobre o conceito de elitização da língua e da cultura apontado por Oliveira e Paiva (2011), em seu artigo crítico à "Narrativa 14", depoimento central do livro "Inglês em escola pública (não) funciona?”. No referido texto, a autora aponta "como o preconceito de que os pobres não devem falar inglês está enraizado na cultura brasileira e como as elites entendem que a língua inglesa é sua propriedade exclusiva" (PAIVA, 2011, p. 36), enquanto discorre sobre os diversos veículos utilizados para disseminar esta noção, sendo um deles a música popular brasileira. Esta postura foi imediatamente identificada por nós com base nos comentários orais feitos pelos alunos, dentre eles: a fala de que literatura é muito difícil ainda mais em língua inglesa; língua inglesa é para poucos e ricos, entre outros. 
Dossiê Especial: Experiências do PIBID na formação inicial e continuada de professores de línguas estrangeiras

HIBARINO \& NODARI (orgs)

Revista X, vol.1, 2015

Diante do quadro observado, o principal desafio dizia respeito a despertar o interesse nos alunos pela literatura, que havia sido notavelmente pequeno por ocasião do trabalho com Shakespeare. O autor norte-americano Edgar Allan Poe foi, então, escolhido por julgarmos que os elementos de terror e mistério, frequentes em seus textos, seriam atrativos aos alunos. Além disso, na época em que a oficina foi realizada, duas séries de TV relacionadas à biografia e à obra do autor estavam sendo transmitidas - Contos do Edgar e The Following - sendo uma delas mencionada por um dos alunos em uma conversa informal. Consideramos positivo o fato de que os alunos pudessem relacionar o conhecimento que iriam obter a estas adaptações, assim como a outras que apresentamos. Tal fator poderia ser mais um incentivo à participação durante a execução das atividades da nossa proposta.

Procuramos, então, desenvolver atividades por meio das quais os alunos pudessem construir sua própria perspectiva sobre a obra do referido autor. Além disso, consideramos viável que eles pudessem identificar o eco que esta possui ao longo da história da literatura, um processo que consideramos importante, pois, como aponta Markus Weininger (2006), para que seja possível o aprendizado da língua, o aluno "não poderá ficar mais no papel passivo de cruzar os braços e 'consumir' a aula do professor como se fosse um programa de TV, para decorar o conteúdo em casa com a finalidade de reproduzi-lo mais tarde.” (WEININGER, 2006, p. 58). Com isto em mente, propusemos que os alunos produzissem suas próprias releituras, pensando em valorizar suas habilidades e gostos pessoais, releituras estas materializadas em produções diversificadas realizadas em inglês, pois, como Weininger já ressalta, "suas atividades autônomas são as pedras que constroem o edifício de sua (futura) competência linguística.” (2006, p. 58). Os trabalhos finais produzidos pelos alunos incluíram representações teatrais em sala e gravadas em vídeo, animações feitas por computador, charge, jornal sensacionalista, histórias em quadrinho, dentre muitas outras.

Como público-alvo desta oficina, tivemos todas as turmas nas quais a professora supervisora lecionava, ou seja, seis turmas de primeiro ano do ensino médio e duas turmas de terceiro ano do ensino médio, todas do ensino regular, do turno da manhã. O quadro abaixo descreve brevemente os procedimentos e as atividades desenvolvidas de acordo com o cronograma que elaboramos para execução da oficina: 
Dossiê Especial: Experiências do PIBID na formação inicial e continuada de professores de línguas estrangeiras

HIBARINO \& NODARI (orgs)

Revista X, vol.1, 2015

\begin{tabular}{|c|l|l|}
\hline Aula & Semana & \multicolumn{1}{c|}{ Observações } \\
\hline 01 & 01 & $\begin{array}{l}\text { Construímos uma apresentação na forma de slides contendo algumas } \\
\text { informações sobre a biografia e as principais características das obras de } \\
\text { Poe. Incluímos resumos de alguns contos, um trecho de um programa de } \\
\text { televisão que abordou o tema, o o trailer do mais recente filme baseado } \\
\text { em Poe, com o ator John Cusack no elenco. O objetivo principal desta } \\
\text { apresentação foi introduzir o tema aos alunos. Nesta aula também } \\
\text { dividimos as turmas em cinco grupos de alunos, os quais receberam: 1) } \\
\text { um roteiro com o cronograma completo da oficina / 2) uma versão } \\
\text { facilitada em inglês do conto O Gato Preto (escolhido por ser curto e de } \\
\text { linguagem acessível) / 3) uma versão traduzida do mesmo conto. Os } \\
\text { alunos deveriam ler o conto para a aula seguinte. A tarefa passada para a } \\
\text { aula seguinte foi diferente para cada grupo, mas no geral os alunos } \\
\text { deveriam preparar um esboço, em inglês, da parte escrita que constaria } \\
\text { nos trabalhos. Caso optassem por uma encenação, por exemplo, deveriam } \\
\text { trazer um esboço dos diálogos a serem seguidos. Os alunos foram ainda } \\
\text { orientados para que solicitassem participação e participassem ativamente } \\
\text { do grupo da oficina no Facebook®. }\end{array}$ \\
\hline 02 & $\begin{array}{l}\text { Nesta aula, programamos discutir o conto com os alunos, partindo do } \\
\text { pressuposto de que o haviam lido durante a semana que se passara. } \\
\text { Também verificamos o esboço de releitura que os grupos haviam } \\
\text { produzido, auxiliando especialmente com as dificuldades relacionadas à } \\
\text { língua inglesa nas produções escritas. Notamos que nossos esforços em } \\
\text { fazê-los se interessarem pelo tema foram eficientes, já que a grande } \\
\text { maioria dos alunos cumpriu com o que foi solicitado. A tarefa para a } \\
\text { semana seguinte seria finalizar o trabalho e preparar a apresentação de } \\
\text { suas produções, fossem elas encenações, cartazes ou histórias em } \\
\text { quadrinhos, dentre outras. }\end{array}$ \\
\hline 03 & $\begin{array}{l}\text { Nesta semana aconteceram as apresentações dos cinco grupos de cada } \\
\text { turma. Algumas das apresentações foram gravadas, por se tratarem de } \\
\text { encenações de diálogos produzidos pelos alunos com o nosso auxílio. }\end{array}$ \\
\hline 03
\end{tabular}

\section{Sobre o trabalho com literatura no ensino de língua inglesa}

Pressupondo que o ensino de línguas, a cultura e a imersão cultural são elementos indissociáveis, decidimos utilizar a literatura de língua inglesa em nossa oficina. Como defende a pesquisadora Sandra McKay,

[a] cultura desempenha um papel significativo no ensino de línguas em, pelo menos, dois aspectos. Primeiro, o conhecimento cultural, que muitas vezes fornece a base para o conteúdo e os temas que são usados em materiais de linguagem e discussões em sala de aula. Em segundo lugar, os padrões 
Dossiê Especial: Experiências do PIBID na formação inicial e continuada de professores de línguas estrangeiras

HIBARINO \& NODARI (orgs)

Revista X, vol.1, 2015

pragmáticos são frequentemente baseados em determinados modelos culturais. (MCKAY, 2003, p. 10, tradução nossa) ${ }^{10}$

Partindo da premissa que o trabalho com o texto literário precisava ser feito de forma diferenciada, selecionamos cuidadosamente os materiais e nos preocupamos com a cultura da qual seriam extraídos. A razão para tais cuidados e preocupação ligava-se ao fato de que já havíamos observado em outros contextos que o texto literário é normalmente trabalhado de uma forma única, forma esta já investigada pelo pesquisador Lynn Mário T. Menezes de Souza (1999), para citar apenas um exemplo. Segundo relato do autor, "o modo dominante das aulas [tanto de literatura quanto naquelas em que se faz uso do texto literário] é o expositivo, onde o professor mantém um monólogo prolongado durante a aula, com pequenas interrupções da parte dos alunos para responder as questões do professor." (de SOUZA, 1999, p. 25, tradução nossa). ${ }^{11}$

Como já apontado, observando a relutância dos alunos diante do trabalho que havia sido desenvolvido com o texto literário (William Shakespeare) e a forma como subestimavam suas capacidades linguísticas e de interpretação, utilizamos as obras de Edgar Allan Poe, originais e adaptadas, por serem escritas em linguagem acessível e nos formatos (conto e poema) que, por serem curtos, não causariam tanto receio ou mesmo resistência por parte dos alunos.

Ainda como justificativa para o uso do texto literário, recorremos ao pressuposto defendido por Stetsenko (2010, apud NODARI, 2012, p. 02) de que a literatura serve como ferramenta pedagógica e cultural quando o objetivo é trabalhar a língua inglesa com o apoio do texto literário. De acordo com Nodari, "como ferramenta cultural, o texto literário apresenta-se inovador ao mesmo tempo em que é representativo da tradição cultural.” (NODARI, 2012, p. 02). Outros teóricos (vide COLLIE; SLATER, 2001), que defendem o uso do texto literário em sala de aula, apontam que este transcende delimitações de tempo e cultura e, portanto, surpreende leitores. O texto literário, além disso, oferece um contexto amplo e vívido no qual personagens de diferentes contextos sociais podem ser representados, outro motivo para considerá-lo uma

\footnotetext{
${ }^{10}$ No original: "Culture plays a significant role in language pedagogy in at least two ways. First, cultural knowledge often provides the basis for the content and topics that are used in language materials and classroom discussions. Secondly, pragmatic standards are frequently based on particular cultural models." (MCKAY, 2003, p. 10).

${ }^{11}$ No original: "... the dominant mode of the classes is the expository mode, where the teacher sustains a prolonged monologue during the class, with only minor interruptions on the part of the learners to answer the questions of the teacher. "(de SOUZA, 1999, p. 25).
} 
Dossiê Especial: Experiências do PIBID na formação inicial e continuada de professores de línguas estrangeiras

HIBARINO \& NODARI (orgs)

Revista X, vol.1, 2015

ferramenta útil no processo de ensino e aprendizagem de uma língua, por promover o envolvimento pessoal dos leitores e apresentar este perfil atemporal.

Sabendo, no entanto, que o texto literário não é escrito com propósitos pedagógicos, mas que pode ser usado com este intuito, optamos por traçar com cuidado o nosso plano de ação e escolhemos, de forma clara, as ferramentas que iriam auxiliar nesse trabalho.

\section{Sobre a utilização de tecnologias no contexto da oficina}

Segundo Paiva (2010), “o conhecimento, atualmente, assume várias formas e o mesmo tema pode ser encontrado no youtube, em apresentações de power point disponibilizadas no slideshare, divulgado no Twitter®, postado e discutido em um blog ou em uma lista de discussão. Todos podem falar ao mesmo tempo de forma multimodal”. (PAIVA, 2010, p.2). Considerando esta perspectiva, ponderamos quanto ao papel da tecnologia como integrante do processo de ensino-aprendizagem nesta oficina e, levando em conta nossa adesão aos diferentes modos de releituras do conto de Edgar Allan Poe, as quais poderiam incluir produção tecnológica, optamos por utilizá-la.

Tendo em vista que, como bolsistas, acompanhamos as aulas da professora durante apenas uma manhã por semana, escolhemos utilizar uma plataforma online para interação e compartilhamento de materiais relacionados à oficina. Sabemos que existem plataformas específicas de ensino à distância, cujos layouts são próprios para fins acadêmicos, a exemplo do Moodle e do Edmodo. Entretanto, optamos pelo Facebook® por sabermos que os alunos já o acessavam com facilidade e diariamente como forma de lazer. Sabíamos que os alunos já o conheciam bem e, portanto, não haveria muitas dificuldades técnicas em relação ao seu uso. Desta forma, criamos um grupo no Facebook ${ }^{\circledR}$ no início da oficina que integrava todas as turmas participantes. Incentivamos os alunos para que, durante o processo, compartilhassem quaisquer materiais encontrados, discutissem o tema escolhido e esclarecessem suas dúvidas. Ao final da proposta, postamos ainda fotos e produções.

Consideramos importante este ambiente de compartilhamento de opiniões e impressões, pois, como salienta Kumaravadivelu (2001) em sua teoria do pós-método, “os professores de língua não podem se dar ao luxo de ignorar a realidade sociocultural que influencia a formação da identidade na sala de aula, ou mesmo separar as necessidades linguísticas dos aprendizes de 
Dossiê Especial: Experiências do PIBID na formação inicial e continuada de professores de línguas estrangeiras

HIBARINO \& NODARI (orgs)

Revista X, vol.1, 2015

suas necessidades sociais.” (KUMARAVADIVELU, 2001, p. 544, tradução nossa) ${ }^{12}$. Tendo este conceito em vista, tal prática tornou-se imprescindível para a quebra da noção de que o aluno vem para a escola apenas e tão somente para aprender de modo passivo, e que suas experiências e conhecimento de mundo não são parte relevante do processo de aprendizado. Outra justificativa para o uso de uma ferramenta tecnológica já conhecida pelos alunos reside no fato de tornar a aprendizagem de uma língua estrangeira minimamente significativa.

É largamente discutido atualmente o conceito de que "os alunos de hoje não são mais as pessoas para as quais nosso sistema educacional foi feito.” (PRENSKY, 2001 apud PAIVA, 2010, p. 9) e, através de nossas pesquisas, pudemos observar que, de fato, não são. Os alunos, atualmente, tendem a tirar fotos do conteúdo escrito no quadro negro, a fazer suas pesquisas no computador e a preferir o conteúdo digitalizado, assim como preferem os conteúdos passados em powerpoint ou vídeos em detrimento dos livros didáticos, pois, em sua maioria, estão familiarizados com ambientes informatizados.

Embora o Colégio Estadual Pilar Maturana tenha enfrentado diversos problemas estruturais desde a inauguração de sua atual sede, alguns espaços na escola se destacam positivamente, a exemplo de sua sala de multimídia. Trata-se de uma sala ampla que pode ser utilizada para exibição de vídeos/filmes com data show, por exemplo. O laboratório de informática também pode ser mencionado como um bom espaço com tecnologia disponível para os alunos. Procuramos aproveitar estes recursos para os objetivos da oficina. Porém, é preciso ressaltar que o fácil acesso ao Facebook® mencionado anteriormente não se refere a esta sala e sim ao acesso doméstico, uma vez que o acesso a mídias sociais na escola não é autorizado aos alunos.

Esta censura se dá, em parte, pela relutância de alguns profissionais em relação ao uso de redes sociais e plataformas midiáticas no ensino em função, muitas vezes, do conteúdo que não 'sofre' controle ou classificação indicativa de faixa etária. Além disso, muitos subestimam, muitas vezes, a capacidade do aluno de diferenciar trabalho e lazer. Grande parte dos alunos fez uso de celulares e outros dispositivos eletrônicos para acessar o grupo no Facebook®, os arquivos digitais disponibilizados nele e para buscar informações sobre o tema no decorrer da

\footnotetext{
${ }^{12}$ No original: “...language teachers can ill afford to ignore the sociocultural reality that influences identity formation in the classroom, nor can they afford to separate the linguistic needs of learners from their social needs." (KUMARAVADIVELU, 2001, p. 544).
} 
Dossiê Especial: Experiências do PIBID na formação inicial e continuada de professores de línguas estrangeiras

HIBARINO \& NODARI (orgs)

Revista X, vol.1, 2015

oficina, e em momento algum esta atitude foi um empecilho à produção dos alunos ou ao desenvolvimento do trabalho.

Como defendido pelo pesquisador Prensky (2001 apud PAIVA, 2010), estes alunos são representantes da agora conhecida geração dos "nativos digitais", que já nascem familiarizados com a internet e com o universo que esta tem a oferecer. De forma semelhante aos alunos das escolas públicas, nós também podemos ser considerados "nativos digitais”, tornando esta geração com que estamos trabalhando e as próximas que estão por vir gerações de nativos digitais aprendendo com nativos digitais, a construir uma cidadania que pode ser entendida como planetária (JORDÃO, 2007).

Tendo em vista que ambas as gerações, tanto a dos alunos quanto a nossa, são nativos digitais, levamos em consideração que ambas cresceram em um mundo fora das fronteiras convencionais. Ambas cresceram com essas fronteiras mais amplas que as das gerações anteriores e, por conta disso, com maior acesso a outras culturas. Acesso este que pode ser facilitado pelo conhecimento e uso da língua inglesa.

Consideramos, porém, que há alguns entraves relacionados à utilização de tais tecnologias na prática de ensino a partir de nossas observações no período inicial no PIBID. Em diversas ocasiões vimos tentativas frustradas de professores e alunos de apresentar vídeos nas TVs multimídia (popularmente conhecida como TV pen drive) ${ }^{13}$, como elas são conhecidas nas escolas estaduais, presentes em todas as salas de aula do colégio, que não funcionavam. Em outros momentos, os usuários tinham dificuldade para adequar seus arquivos aos formatos exigidos por aquela TV, o que causava transtornos, adiamentos, frustrações. Além disso, o data show da escola é guardado junto com outros dispositivos eletrônicos em uma sala separada sob a supervisão de uma funcionária. Portanto, não fica instalado, e é preciso que o professor reserve ao menos vinte minutos do seu tempo para instalá-lo. Outra dificuldade relacionada à utilização do equipamento de data show é a ausência de um computador/laptop disponível para conexão com ele. Já vimos professores da escola levando seus próprios laptops para poder garantir que o que havia sido planejado pudesse ser feito, e nós também o fizemos durante a nossa oficina. Observando e vivendo estes empecilhos, foi possível perceber que apesar de a integração da

\footnotetext{
${ }^{13}$ Esta ferramenta é encontrada em todas as salas de aula das escolas estaduais do Paraná. Trata-se de uma televisão com a qual os professores podem projetar filmes, por exemplo, com ajuda de um flash drive onde estes seriam gravados com antecedência.
} 
Dossiê Especial: Experiências do PIBID na formação inicial e continuada de professores de línguas estrangeiras

HIBARINO \& NODARI (orgs)

Revista X, vol.1, 2015

tecnologia ao ensino ser inexorável, ela ainda carece de um processo de adaptação, de treinamento, e de facilitação para que a maior quantidade possível de profissionais e alunos possam usufruir dela.

A tecnologia, junto com o ensino de língua estrangeiras, aproximou fronteiras. Com o maior acesso à internet conhecemos culturas, pessoas e línguas diferentes da nossa. Com isso, o jovem pode olhar com mais atenção sua própria cultura, sua língua nativa. Então, da mesma forma como a tecnologia e a língua, a cidadania está em constante mudança.

Uma vez que os sentidos se constroem na língua, com a língua e pela língua [...], então aprender línguas é aprender procedimentos interpretativos, e aprender procedimentos interpretativos criticamente é aprender a exercer a cidadania - é construir sentidos dentro da consciência das relações de poder em seus aspectos positivos e negativos; é estar em processo de letramento crítico, sendo capaz de elaborar entendimentos sobre o que possibilita a construção de certos pontos de vista e suas implicações para a vida do e no planeta. (JORDÃO, 2007. p. 22)

Entendendo que o conhecimento pode surgir do "conflito" entre diferentes visões de mundo e, que cada visão de mundo carrega consigo uma concepção de poder e se há uma concepção de poder existe uma relação de prestígio, então a construção do conhecimento se dará a partir da relação de prestigio entre determinadas comunidades. Mesmo no LC existem hierarquizações que "(...) não são uma consequência de características internas ou essenciais das ideias ou dos sujeitos: a hierarquização e os julgamentos de valor que fazemos são consequência de formas de entendimento adquiridas culturalmente e atribuídas aos objetos que construímos." (JORDÃO, 2007, p. 23). Nesse caso, de duas concepções de conhecimento divergentes, surgiriam outras possibilidades de entendimento dessas formas de conhecimento.

Considerando esta visão, ao solicitar dos alunos que discutissem os mesmos textos e compartilhassem suas impressões entre si e conosco, foi possibilitado o desenvolvimento de novas construções de sentidos acerca das obras de Edgar Allan Poe, assim como foi possibilitada a produção de releituras partindo das interpretações pessoais dos alunos, inserindo nelas suas experiências, conhecimento de mundo, habilidades particulares e visões particulares, remetendo ao que é proposto por Kumaravadivelu (2001), quando considera que

(...) o ensino de línguas, para ser relevante, deve ser sensível a um determinado grupo de professores ensinando um determinado grupo de aprendizes buscando um determinado conjunto de metas dentro de um determinado contexto embutido em um determinado meio sociocultural. 
Dossiê Especial: Experiências do PIBID na formação inicial e continuada de professores de línguas estrangeiras

HIBARINO \& NODARI (orgs)

Revista X, vol.1, 2015

Uma pedagogia de particularidade é, então, antitética à noção de que é possível definir um conjunto de objetivos pedagógicos e realizáveis através de um conjunto de princípios e procedimentos pedagógicos. (KUMARAVADIVELU, 2001, p. 538, tradução nossa) ${ }^{14}$.

Tanto a proposta do pós-método quanto a compreensão do que seja LC estão em consonância com o entendimento que podemos construir do conceito de Inglês como Língua Internacional (ILI). Apesar de sabermos que há diferentes terminologias sendo usadas para se referir aos tipos de "Inglêses" que são estudados e usados por falantes de países outros que não aqueles em que o inglês é primeira ou segunda língua (países dos círculos interno e externo de falantes de inglês segundo BRAJ KACHRU, 1986), acreditamos que a variação conhecida pela alcunha de inglês como língua internacional dê conta mais adequadamente do tipo de inglês que se estuda e os objetivos por trás da aprendizagem deste em contexto de universidades brasileiras e escolas públicas do estado do Paraná. Acreditamos que isso se dê por concordarmos com Sharifian (2009) quando este afirma que o inglês viajou para muitas partes do mundo e tem servido para diferentes propósitos, para melhor ou para pior, por escolha ou imposição. ${ }^{15}$ No caso da escola pública, há professores ensinando um determinado grupo de aprendizes que buscam um conjunto de metas dentro de um determinado contexto embutido em um dado meio sociocultural. Nesse contexto determinado, o que se faz necessário é o trabalho não apenas de letramento na língua estrangeira, mas um letramento crítico que dê conta de colocar os aprendizes a questionar o porquê de estarem estudando uma determinada língua estrangeira, no caso, por imposição, e que os prepare para interagir em um mundo globalizado onde cada vez mais pessoas estão a usar o ILI para comunicação em ambientes de estudo, trabalho e lazer.

\section{Considerações finais}

Como todas as línguas, o inglês conta com inúmeras variantes linguísticas e, como mencionado anteriormente, existe uma grande disseminação da língua inglesa pelo mundo. A pesquisadora McKay argumenta que:

\footnotetext{
${ }^{14}$ No original: "language pedagogy, to be relevant, must be sensitive to a particular group of teachers teaching a particular group of learners pursuing a particular set of goals within a particular institutional context embedded in particular sociocultural milieu. A pedagogy of particularity, then, is antithetical to the notion that there can be one set of pedagogic aims and objectives realizable through one set of pedagogic principles and procedures." (KUMARAVADIVELU, 2001, p. 538)

${ }^{15}$ No original: "For better or worse, by choice or force, English has 'traveled' to many parts of the world and has been used to serve various purposes.” (SHARIFIAN, 2009, p. 1).
} 


\section{Dossiê Especial: Experiências do PIBID na formação inicial e continuada de professores de línguas estrangeiras \\ HIBARINO \& NODARI (orgs) \\ Revista X, vol.1, 2015}

O número crescente de pessoas no mundo que têm alguma familiaridade com o Inglês permite que este atue como língua para uma comunicação mais ampla com uma grande variedade de propósitos, contribuindo para o seu status de língua franca global. No processo de alcance deste status, a própria natureza do Inglês mudou no que diz respeito a quantos de seus falantes fazem uso de Inglês e como o Inglês se relaciona com a cultura. (MCKAY, 2003, p. 2, tradução nossa). ${ }^{16}$

Entende-se que a língua inglesa é instrumento facilitador da comunicação e da troca, de qualquer tipo, entre indivíduos de diferentes nações. Considera-se, portanto, que é necessário que os professores tenham cuidado ao ensinar a língua inglesa, mostrando que não há uma única possibilidade de falar essa língua, se é que essa noção algum dia foi verdadeira. No momento em que o professor mostra ao aluno outras variantes, este percebe outras possibilidades de aprendizado, outros contextos de aplicação do que está estudando.

Além disso, há que se ressaltar que o trabalho feito em escola pública com texto literário pode acontecer se algumas condições forem observadas quando da condução deste tipo de proposta. Mesmo que o texto literário seja usado apenas como pretexto para o ensino da língua, a familiaridade do aluno com uma ferramenta cultural que poderia antes ser considerada como algo muito distante ou difícil já se iniciou.

Um objetivo maior ainda pode ser atingido com este trabalho, qual seja, o da formação de leitores informados e críticos. A ideia de que os textos podem ser lidos e entendidos de diferentes formas já satisfaz parcialmente o conceito de LC. Através do uso do texto literário em língua inglesa em uma oficina com alunos de ensino médio de uma escola pública foi possível, além de dar acesso à estrutura da língua aos alunos, ingressá-los na cultura de países que tomam o inglês por língua nativa. Ao mesmo tempo esta prática possibilitou que os alunos pudessem inserir e valorizar suas próprias vivências, permitindo uma variedade rica de interpretações e releituras de um conto específico de Edgar Allan Poe — na forma de histórias em quadrinhos, poemas e mesmo um telejornal, para citar apenas alguns exemplos — , assim como a conscientização

16 No original: "The growing number of people in the world who have some familiarity with English allows English to act as a language of wider communication for a great variety of purposes, contributing to its status as a global lingua franca. In the process of achieving this status, the very nature of English has changed in terms of how many of its speakers make use of English and how English relates to culture. In order to develop an appropriate pedagogy for EIL, it is essential to examine the nature of these changes." (MCKAY, 2003, p. 2). 
Dossiê Especial: Experiências do PIBID na formação inicial e continuada de professores de línguas estrangeiras

HIBARINO \& NODARI (orgs)

Revista X, vol.1, 2015

destes mesmos alunos sobre o conceito de língua inglesa como patrimônio mundial, não hierarquizado e/ou restrito a determinados grupos de poder aquisitivo maior.

De forma mais ampla, o PIBID oportunizou e oportuniza a desconstrução de um modo dominante de dar aulas, uma vez que permite que bolsistas, professores supervisores e alunos se coloquem em diferentes posições, construindo conhecimento juntos. Os alunos, na proposta relatada, se deslocaram de suas posições passivas para a de agentes, ao entenderem, interpretarem e reinterpretarem o que seria considerado exemplo de produção do cânone literário, mostrando a atemporalidade do autor e de sua produção e mostrando que é possível ler literatura em língua inglesa no ensino médio de uma escola pública.

\section{Agradecimentos}

Agradecemos à CAPES pela concessão das bolsas PIBID que possibilitaram a realização dessa pesquisa.

\section{Referências}

COLLIE, J.; SLATER, S.. Literature in the language classroom. Cambridge: Cambridge University Press, 2001 [1987].

DE SOUZA, L. M. T. M.. "On awe and awareness - the literary text in the classroom". Revista Ilha do Desterro. UFSC: Florianópolis, n. 37. Jul/Dez. 1999, Pp. 21-33

IDEB. Disponível em: 〈http://portal.inep.gov.br/web/portal-ideb>. Acesso em 17 jul. 2014.

JORDÃO, C. M. “As lentes do discurso: letramento e criticidade no mundo digital". Trabalhos em Linguística Aplicada. v.1, n.46, Pp. 19-29, Jan./Jun.2007.

KUMARAVADIVELU, B. "Toward a postmethod pedagogy". TESOL Quarterly, v. 35, n. 4, 2001, Pp. 537-60.

KUMARAVADIVELU, B. Understanding language teaching: from method to postmethod. Mahwah: Lawrence Erlbaum Associates Publishers, 2006.

MCKAY, S. L. "Toward an appropriate EIL pedagogy: re-examining common ELT assumptions". International Journal of Applied Linguistics. v. 13, n. 1, 2003, p. 1-22.

NODARI, J. I. “O texto literário na aula de LE - construindo um lugar alternativo para a prática da agência discente/docente". Revista de Letras. UTFPR: Curitiba, v. 15, n. 01. Ago. 2012, Pp. 01-17.

PAIVA, V. L. M. de O. e. "A tecnologia na docência em línguas estrangeiras: convergências e tensões”. IN: SANTOS, L. L. de C. P. (Org.). Convergências e tensões no campo da formação e do trabalho docente. Belo Horizonte: Autêntica. v. V, 2010, Pp. 595-613. 
Dossiê Especial: Experiências do PIBID na formação inicial e continuada de professores de línguas estrangeiras

HIBARINO \& NODARI (orgs)

Revista X, vol.1, 2015

"Ilusão, aquisição ou participação". IN: LIMA, D. C. de (Org.).

Inglês em escolas públicas não funciona: uma questão de múltiplos olhares. São Paulo: Parábola, 2011, Pp. 33-46.

SHARIFIAN, F. (ed.). English as an international language. Bristol, Buffalo and Toronto: Multilingual Matters, 2009.

WEININGER, M. "Do aquário em direção ao mar aberto. Mudanças no papel do professor e do aluno”. IN: LEFFA, V. J. (Org.). O professor de línguas. Construindo a profissão. 2. ed. Pelotas: Educat, 2006, Pp. 51-68. 